\title{
A Study of Outcome of Open Supracondylar Fracture Femur Treated with Ilizarov Fixator as Primary Management
}

\author{
Ananthula Krishna Reddy ${ }^{1}$, Rapaka Radhakrishna² \\ ${ }^{1}$ Associate Professor, Department of Orthopaedics, Osmania Medical College, Hyderabad, Telangana, India. \\ ${ }^{2}$ Associate Professor, Department of Orthopaedics, Osmania Medical College, Hyderabad, Telangana, India.
}

\section{ABSTRACT}

\section{BACKGROUND}

Supracondylar fractures with intercondylar extension of distal femur are often due to high energy trauma. Conservative line of management is obsolete because of associated complications. Varieties of treatment modalities are available and are challenging. Fixation with conventional methods are difficult. Intramedullary devices are also not suitable in such situation. Conventional unilateral knee spanning external fixators and hybrid fixators can cause problems like knee joint stiffness and the issue of bone loss is difficult to deal with. To address this problem, we used Ilizarov ring fixator in the management of comminuted supracondylar fractures with intercondylar extension of the distal femur (C2 and C3 Type according to AO/ASIF Classification).

\section{METHODS}

In our study in Osmania General Hospital, 20 patients with open fracture of distal femur were operated. The method used for fracture fixation was primary Ilizarov ring fixation. All cases were fresh, and were in the age group of 22 yrs. to 68 yrs. with the mean age of 45 years. The duration of follow up ranged from 3 months to 1 year. The results were assessed using Neer's Scoring System (Table-1), with main emphasis on range of mobility of knee joint.

\section{RESULTS}

Among the 20 patients operated, 13 patients (65\%) showed radiological union within 18 weeks. Six patients had developed pin tract infections. Average range of flexion achieved in our study in more than $50 \%$ of patients was $110^{\circ}$. In our study, we obtained Neer's knee score with an average of 76 (50-98) (satisfactory to excellent).

\section{CONCLUSIONS}

The Ilizarov technique allows early restoration of function of the limb which results in adequate stimulus for early soft tissue and bone healing. Proper understanding of the biological and biomechanical principles of the Ilizarov method and careful application give excellent results in almost all cases of open supra condylar fractures.

\section{KEY WORDS}

Open Supracondylar Femoral Fractures, Primary Ilizarov External Ring Fixator, Radiological Union, Knee Joint Stiffness, Physiotherapy, Knee Range of Motion
Corresponding Author: Dr. Rapaka Radhakrishna, 3-7-62/371, Southend Park, G. S. I. Post, Mansoorabad, Hyderabad-500068, Telangana, India. E-mail:drrapaka@yahoo.com

DOI: $10.14260 / \mathrm{jemds} / 2019 / 657$

Financial or Other Competing Interests: None.

How to Cite This Article:

Reddy AK, Radhakrishna R. A study of outcome of open supracondylar fracture femur treated with ilizarov fixator as primary management. Evolution Med. Dent. Sci. 2019;8(40):3024-3027, DOI: $10.14260 /$ jemds/2019/657

Submission 03-07-2019,

Peer Review 21-09-2019,

Acceptance 27-09-2019,

Published 07-10-2019. 


\section{BACKGROUND}

Supracondylar fractures with intercondylar extension in the distal femur are often attributed to high energy trauma. Strong deforming muscle forces, proximity to the knee joint and vicinity of vascular structures are some of the important factors to consider during their management. ${ }^{1}$ Complications like angular deformity, malunion and joint incongruity make the conservative line of management obsolete. ${ }^{1}$ Various modalities of treatment are available like a dynamic condylar screw, fixed angle blade plate, locking plates and even intramedullary nails ${ }^{2}$. Satisfactory outcomes can be obtained with these fixation devices, especially in extra-articular Type A or Type B supracondylar fractures as per AO/ASIF classification.2,3 But treatment of severely comminuted supracondylar fractures with intercondylar extension is challenging. 1,2,4,5 In the presence of severe comminution and intercondylar extension, fracture reduction and fixation with conventional methods becomes difficult. ${ }^{1}$ Intramedullary devices are also not suitable in such situation. ${ }^{2}$ Conventional unilateral knee spanning external fixators and hybrid fixators can be useful in such situations ${ }^{3,6}$ but they may cause problems of knee joint stiffness and the issue of bone loss is difficult to deal with them. This stimulated us to perform a study on the use and application of Ilizarov ring fixator for effectively managing severely comminuted supracondylar fractures of femur with intercondylar extension in the distal femur (C2 and C3 Type as per AO/ASIF Classification). The Ilizarov ring fixator is reserved for severe comminuted factures and also injuries with poor overlying soft tissues ${ }^{7}$ but it can also effectively manage the issues like bone loss, facilitates limb length restoration, early weight bearing and mobilization. ${ }^{8,9}$

The aim of our study was to evaluate the efficacy of Ilizarov external ring fixator in the management of open supra condylar fracture femur in adults.

\section{METHODS}

It is a prospective interventional study, with 20 patients admitted with open distal femoral fractures, which included supracondylar fractures with intercondylar extension. All the cases were admitted for free treatment. Informed consent was taken in prescribed proformas, possible outcome of procedure explained.

\section{Inclusion Criteria}

Patients aged 20 years and above having distal third femoral fractures and open fractures were included in the study.

\section{Exclusion Criteria}

Patients with fractures of lower third of femur due to pathological aetiology other than osteoporosis, patients under 20 years of age, patients managed conservatively for other medical reasons, patients with lower third femoral fractures with neurovascular deficit and patients with closed fractures were excluded from the study.

Fractures were classified with the help of plain X-rays as per AO-ASIF classification. ${ }^{10,11}$ Preoperatively ring placement position was assessed and planned on radiographs along with transfixation wires, olive wires, Schantz pins and cc screws in the affected bone.

The final fracture reduction was checked under fluoroscopic control and any malalignment corrected by changes in the articulations of the frame. In 3 patients, the frame was extended up to the proximal tibia to achieve good stability of fixation. The tibial rings were removed six weeks after initial surgery in outpatient department as small procedure under mild sedation.

Postoperative measures were: Limb elevation and strict immobilization for 2 to 3 days. During this period, partial weight bearing with crutches was allowed in these patients under our supervision. Knee mobilization was allowed on an average of 4 weeks (ranging from, 2-6 weeks), with a hinged knee brace. ${ }^{12,13}$ Full weight bearing was allowed after 2 weeks with a range, from 2-4 weeks. The tibial frame was removed after 8 weeks on average, ranging from, 6-11 weeks. The femoral frame was removed on out-patient basis at 19 weeks on average, ranging from, 17-28 weeks. A hinged knee brace was applied for a further 4 to 6 weeks.

Statistical analysis was done with Neer's functional and anatomic scoring ${ }^{14}$. (Table- I) (Software MS Office 360).

\begin{tabular}{|c|c|}
\hline Pain & Number \\
\hline No Pain & 20 \\
\hline Intermittent & 16 \\
\hline With fatigue & 12 \\
\hline Restrict function & 8 \\
\hline Constant or at night & 4 \\
\hline extreme & 0 \\
\hline \multicolumn{2}{|l|}{ Function (Mobility) } \\
\hline as before injury & 20 \\
\hline Mild restriction & 16 \\
\hline Restricted; climb stairs sideways & 12 \\
\hline Cane or severe restriction & 8 \\
\hline Crutches or brace & 4 \\
\hline Totally disabled & 0 \\
\hline \multicolumn{2}{|l|}{ Range of Motion in Knee } \\
\hline Normal or more than 135 degrees & 20 \\
\hline 100 degrees & 16 \\
\hline 80 degrees & 12 \\
\hline 60 degrees & 8 \\
\hline 40 degrees & 4 \\
\hline Less than 20 degrees & 0 \\
\hline \multicolumn{2}{|l|}{ Work } \\
\hline As before surgery & 10 \\
\hline Regular but with handicap & 8 \\
\hline Regular but with change & 6 \\
\hline Light work & 4 \\
\hline Minimal work & 2 \\
\hline Totally disabled & 0 \\
\hline Gross Anatomy & Number \\
\hline Thickening only & 15 \\
\hline 5 degrees angulation or $0.5 \mathrm{~cm}$ short & 12 \\
\hline 10 degrees angulation or $2.0 \mathrm{~cm}$ short & 9 \\
\hline 15 degrees angulation or $3.0 \mathrm{~cm}$ short & 6 \\
\hline Union but with greater deformity & 3 \\
\hline Non-union or chronic infection & 0 \\
\hline \multicolumn{2}{|l|}{ Roentgenogram } \\
\hline Normal or near normal & 15 \\
\hline 5 degrees angulation or $0.5 \mathrm{~cm}$ displacement & 12 \\
\hline 10 degrees angulation or $1.0 \mathrm{~cm}$ displacement & 9 \\
\hline 15 degrees angulation or $2.0 \mathrm{~cm}$ displacement & 6 \\
\hline Union but with greater deformity and arthritis & 3 \\
\hline Non-union or chronic infection & 0 \\
\hline Total Score & Outcome Assessment \\
\hline$>85$ & excellent \\
\hline $70-85$ & satisfactory \\
\hline $55-69$ & unsatisfactory \\
\hline$<55$ & Failure \\
\hline \multicolumn{2}{|c|}{$\begin{array}{c}\text { Table 1. Neer's Criteria for (1) Functional Outcome in } \\
\text { Supracondylar Fractures of Femur, (2.) Anatomic (30 Points): Gross } \\
\text { Anatomy and Roentgenogram, The Higher the Total Score, the } \\
\text { Greater the Function }\end{array}$} \\
\hline
\end{tabular}




\section{RESULTS}

\begin{tabular}{|c|c|c|}
\hline Total Score & Outcome Assessment & Percentage \\
\hline$>85$ & Excellent & 25 \\
\hline $70-85$ & Satisfactory & 65 \\
\hline $55-69$ & Unsatisfactory & -- \\
\hline$<55$ & Failure & 10 \\
\hline \multicolumn{2}{|c|}{ Table 2. Our Results as per Neer's Criteria } \\
\hline
\end{tabular}

\begin{tabular}{|c|c|c|}
\hline Classification Type & Number of Pts. & Percentage \\
\hline Mullers A1 & 1 & 5 \\
\hline A2 & 5 & 25 \\
\hline A3 & 4 & 20 \\
\hline B 1 & - & - \\
\hline B2 & - & - \\
\hline B3 & - & - \\
\hline C1 & 1 & 5 \\
\hline C2 & 5 & 25 \\
\hline C3 & 4 & 20 \\
\hline Total & $\mathbf{2 0}$ & $\mathbf{1 0 0}$ \\
\hline \multicolumn{2}{|c}{ Table 3. Type of Fracture Classification } \\
\hline
\end{tabular}

\begin{tabular}{|c|c|c|}
\hline Union (Weeks) & Number of Cases & Percentage \\
\hline$<16$ weeks & -- & -- \\
\hline $16-18$ weeks & 13 & 65.00 \\
\hline $19-20$ weeks & 7 & 35.00 \\
\hline $21-22$ weeks & -- & -- \\
\hline Delayed union & -- & -- \\
\hline Non union & -- & -- \\
\hline Total & 20 & 100.00 \\
\hline \multicolumn{3}{|c}{ Table 4. Radiological Union } \\
\hline
\end{tabular}

In our study, we operated upon 20 patients with femoral fractures. All cases had history of very recent and fresh trauma. 17 patients were male and 3 were female patients. The mean age was 45 years ranging from 22 yrs. to 68 yrs. All the patients in this study underwent surgery by primary Ilizarov ring fixator ${ }^{15}$. All patients were operated within 8 days of initial injury. Average time taken for surgery was 120 minutes, shortest being 90 minutes and longest being 180 minutes. ${ }^{16}$ Of the 20 patients, $13(65 \%)$ showed good radiological signs of fracture union within 18 weeks. Only six patients had complication of pin tract infections, Average range flexion achieved in this study in more than $50 \%$ of patients was $110^{\circ}$. Out of the 20 patients in the study only 2 patients had limb length discrepancy by less than $1 \mathrm{~cm}$ and 1 patient had shortening of around $3 \mathrm{~cm}$. The average duration of follow up ranged from 3 months to 18 months. In this study very few patients had varus or valgus mal- alignment.

\section{DISCUSSION}

In this study of 20 patients with distal femur fractures which included supracondylar fracture with intercondylar extension, were treated by Ilizarov ring fixator. Overall final results of outcome of surgical management of fracture of distal femur by using Ilizarov ring fixator was assessed in terms of restoring lost knee function in terms of range of motion by using Neer's Score ${ }^{14}$. (Functional and Anatomic) (Table-I)

The Ilizarov external ring fixator when used for the treatment of comminuted distal femur fractures, namely supracondylar and intercondylar fractures has many advantages ${ }^{16,17}$ namely shorter time taken for surgery, minimal blood loss, and since there is minimal surgical exposure and no periosteal stripping, the chances of quicker soft tissue healing and union of the fracture are maximum, along with greater mechanical stability than with a monolateral external fixator. ${ }^{17}$ The Ilizarov ring fixator system with its diverging olive wires gives good stability and a firm compression effect on the condyles $7,18,19$. The tensioned small diameter wires across the bone gave sufficient stability, even in osteoporotic bone. In accordance with current concepts of the Ilizarov technique, we used half threaded Shanz pins in proximal femur. This construct is safe and also comfortable for the patient in this part of limb, namely the thigh. It is also possible at any point time to correct angular malalignment in any stage of treatment. 19

Not only in our study but also and in various other studies, the most disabling complication was loss of knee range of movement.1,2 The main contributing factors for this complication being the anatomical type of the fracture and the severity of associated soft-tissue damage. The wires and pins used in the femur pass through the bulk of the quadriceps muscle, which hinder the movement of the knee while the fixator is in place by preventing effective muscular contraction of the muscle.

In our present study, we found, the use of an Ilizarov external ring fixator in the treatment of Gustilo-Anderson type IIIB supracondylar fractures offers several advantages, although the indications for its use are very specific. ${ }^{12,20}$ Based on the inferences drawn in our study, we suggest adopting Ilizarov external ring fixator as primary treatment method for functional limb salvage after open high-energy injuries. The Ilizarov external ring fixator is safe and versatile, and also effective in providing much needed stability which permits early functional rehabilitation. ${ }^{21}$ There is no need for other plastic surgery procedures like free and local skin flaps as this procedure takes care of soft tissues and skin along with fracture healing. ${ }^{10,21}$

A good range of knee flexion of $0{ }^{0}$ to $110^{\circ}$ is necessary to carryout activities of daily living without much strain. ${ }^{22}$ In our study mean knee range of movements is $112^{0}$ with a range from $65^{0}$ to $130^{\circ}$. Huston et al in their study had knee range of movements $0^{0}$ to $92^{\circ}$. Arazi et al..$^{2}$, the knee range of movements at the final follow-up was $105^{\circ}$ ranging from $35^{\circ}$ to $130^{\circ}$. Proper positioning and application of tension wires and hinges for knee range of movements appear to improve the final outcome of knee range of movements ${ }^{23}$. In spite of achieving fracture union with satisfactory alignment, motion of the knee was uniformly limited. Which may be attributed to the high-energy injury, involving articular comminution and bone loss, with extensor mechanism disruption. ${ }^{24}$

Of the 20 patients, $13(65 \%)$ showed radiological union within 18 weeks. Only six patients had problem of pin tract infections, Average range of motion of flexion achieved in our study by more than $50 \%$ of patients was good $110^{\circ}$. In our study there was shortening of one $\mathrm{cm}$ in two patients and $3 \mathrm{~cm}$ in one patient, Arazi et al had nine cases with shortening of more than $2.5 \mathrm{~cm}$ and Kumar et al had $40 \%$ of the supracondylar fractures with $4 \mathrm{~cm}$ shortening and another $40 \%$ had $1.5 \mathrm{~cm}$ shortening.

Arazi et $\mathrm{al}^{2}$ and Kumar et al had pin tract infection in 21\% of patients ${ }^{3}$ whereas Ramesh et al had pin tract infections in $38 \%$ of patients ( 6 of 13 ) In our study 30 of patients had pin tract infection who were treated with antibiotics and regular 
dressings, none of them had severe infection or loosening of implant resulting in implant removal. Arazi et al in their study of primary Ilizarov ring fixator for supra condylar fracture achieved radiological union at mean interval of 16 weeks $(10$ to 24), Ramesh et al achieved radiological union at a mean interval of 19 weeks(16-24), in our study we achieved radiological union at a mean interval of 18 weeks. Delay is probably due to all cases in study are open which inherently have delayed union. In our study we obtained Neer's knee score with an average of 76 (50-98)

\section{CONCLUSIONS}

Ilizarov technique allows early functional restoration of the limb movements which augments soft tissue and bone healing. Proper selection of patients is of utmost importance and assessing patient compliance is also essential for the successful application of the Ilizarov technique. Good Physiotherapy support along with functional use of the limb from the first week after application of the fixator is essential for successful treatment of the fracture. Ilizarov technique is the treatment of choice for open comminuted fractures of long bones, including supracondylar fractures of femur.

\section{REFERENCES}

[1] O'BRIEN PJ. Fractures of the distal femur. Fractures in Adults 2001;2:1731-73.

[2] Arazi M, Memik R, Ögün TC, et al. Ilizarov external fixation for severely comminuted supracondylar and intercondylar fractures of the distal femur. The Journal of Bone and Joint Surgery British 2001;83(5):663-7.

[3] Kumar P, Singh GK, Singh M, et al. Treatment of Gustilo grade III B supracondylar fractures of the femur with Ilizarov external fixation. Acta Orthopaedica Belgica 2006;72(3):332-6.

[4] Siliski JM, Mahring MA, Hofer HP. Supracondylarintercondylar fractures of the femur. Treatment by internal fixation. The Journal of Bone and Joint Surgery American 1989;71(1):95-104.

[5] Canale ST, Beaty JH. Campbell's operative orthopaedics Ebook. 12th edn. Elsevier Health Sciences 2012.

[6] Ali F, Saleh M. Treatment of isolated complex distal femoral fractures by external fixation. Injury 2000;31(3):139-46.

[7] Ilizarov GA. Transosseous osteosynthesis: theoretical and clinical aspects of the regeneration and growth of tissue. Springer Science \& Business Media 2012.
[8] Thomas HO. Fractures in adult. Quoted by Rockwood CA Green DP. 1972;4:1972-93.

[9] Steinman F. Quoted by Rockwood CA, Green DP. Fractures in adult. 1972;4:1996-93.

[10] Stewart MJ, David ST, Wallace SL Jr. Fractures of the distal third of the femur: a comparison of methods of treatment. JBJS 1966;48(4):784-807.

[11] Watson-Jones R. Fracture repair. In: Wilson NJ, edr. Watson-Jones Fractures and Joint Injuries of the Hand. Vol. 1. Barcelona: Salvat 1980:p. 11-47.

[12] Charnley J. The closed treatment of common fractures. $4^{\text {th }}$ edn. Cambridge: Cambridge University Press 2005.

[13] BANKS HH. The healing of intra-articular fractures. Clinical Orthopaedics and Related Research (1976-2007). 1965;40:17-29.

[14] Neer CS 2nd, Grantham SA, Shelton ML. Supracondylar fracture of the adult femur: a study of one hundred and ten cases. JBJS 1967;49(4):591-613.

[15] Wardlaw D, Mclauchalan J, Pratt DJ, et al. A biomechanical study of cast brace treatment of femoral shaft fractures. JBJS Br 1981;63-B(1):7-11.

[16] Olerud S. Operative treatment of supracondylar-condylar fractures of the femur: technique and results in fifteen cases. JBJS 1972;54(5):1015-32.

[17] Zickel RE, Fietti JV Jr, Lawsing JF, et al. A new intramedullary fixation device for the distal third of the femur. Clinical Orthopaedics and Related Research 1977;(125):185-91.

[18] Brown A, D'Arcy JC. Internal fixation for supracondylar fractures of the femur in the elderly patient. The Journal of Bone and Joint Surgery Br 1971;53(3):420-4.

[19] Riggins RS, Garrick JG, Lipscomb PR. Supracondylar fractures of the femur a survey of treatment. Clinical Orthopaedics and Related Research 1972;82:32-6.

[20] Enneking WF, Horowitz M. The intra-articular effects of immobilization on the human knee. JBJS 1972;54(5):97385.

[21] Connolly JF, Dehne E, Lafollette B. Closed reduction and early cast-brace ambulation in the treatment of femoral fractures. II. Results in one hundred and forty-three fractures. JBJS 1973;55(8):1581-99.

[22] Pavel AL, Smith RL, Ballard A, et al. Prophylactic antibiotics in clean orthopaedic surgery. JBJS Am 1974;56(4):777-82.

[23] Schatzker J, Horne G, Waddell J. The Toronto experience with the supracondylar fracture of the femur, 1966-1972. Injury 1974;6(2):113-28.

[24] Gustilo RB, Anderson JT. Prevention of infection in the treatment of One Thousand and Twenty-Five open fractures of long bones: retrospective and prospective analyses. JBJS 1976;58(4):453-8. 